\title{
Research on new technology for offshore heavy oil thermal recovery with rod pumping
}

\author{
Yanqun $\mathrm{Yu}^{1,2} \cdot$ Zongyu Chang ${ }^{1} \cdot$ Yaoguang $\mathrm{Qi}^{2} \cdot$ Dehua Feng ${ }^{2}$
}

Received: 22 February 2017/Accepted: 23 September 2017/Published online: 3 October 2017

(C) The Author(s) 2017. This article is an open access publication

\begin{abstract}
The high-efficient development of heavy oil is difficult for offshore oil field. Based on the mature technology of onshore heavy oil thermal recovery, a new rod pumping technology of "heavy oil steam stimulation along with conventional sucker rod pumping system" is proposed. According to the structure space of aimed offshore platform, we designed one new kind of miniature hydraulic pumping unit with long-stroke, low pumping speed and compact structure. The paper also studies the offshore heavy oil thermal recovery well safety technology, establishes a leakage model of wellhead sealing and a mechanical model of sealed rubber sleeve on downhole nonlinear large deformation. The study shows that a series of equipment for offshore rod pumping oil recovery and the key technology of well safety lay a solid foundation for carrying out rod pumping of offshore heavy oil thermal recovery.
\end{abstract}

Keywords Offshore platform - Thermal recovery of heavy oil - Oil recovery with rod pumping · Hydraulic pumping unit $\cdot$ Wellhead safety $\cdot$ Downhole safety

Yanqun $\mathrm{Yu}$

yuyq_hdpu@126.com

1 College of Engineering, Ocean University of China, Qingdao 266100, Shandong Province, China

2 College of Mechanical and Electronic Engineering, China University of Petroleum, 66 Changjiang West Road, Qingdao Economic Development Zone, Qingdao 266580, Shandong Province, China

\section{Introduction}

$25 \%$ of proved reserves and $45 \%$ of ultimate recoverable reserves on earth are from the ocean. The future focus of the world's oil production will gradually shift from onshore to offshore (Lea et al. 2011; Shariatinia et al. 2013; Terdre 2011; Denney 2012). The main producing areas of Chinese offshore oilfield have transited from northern oil fields of South China Sea in last century to Bohai oilfield nowadays (Guo et al. 2010; Zhou 2007; Sun et al. 2013). Currently, proved oil reserves with viscosity above $350 \mathrm{mPa} s$ in Bohai Bay region are over $7.41 \times 10^{8} \mathrm{t}$ and un-producing proved reserves reach up to $6.5 \times 10^{8} \mathrm{t}$, which accounts for $87.3 \%$ of the total ( $\mathrm{Li}$ et al. 2016). Therefore, research on high-efficient development of offshore heavy oil occupies a pivotal position in reserve discovery and recovery, productivity construction and oilfield production in Bohai Bay region.

Steam stimulation, of easy operation, quick results, wide application to various types of heavy oil reservoirs, is the current main technology for heavy oil production. Due to limitation of platform space, electric submersible pump is the main lifting equipment of offshore oil recovery (Gholamzadeh et al. 2010; Dong et al. 2008).

However, the steam temperature can reach up to $300{ }^{\circ} \mathrm{C}$, which is higher than the limit working temperature $\left(250^{\circ} \mathrm{C}\right)$, of the current offshore oil production equipmentelectric submersible pump. The pump units and the cables have low-temperature resistance, which has influence on the temperature and dryness of the implanted steam, thereby affecting the stimulation effect. Current offshore heavy oil thermal recovery steam stimulation process is: remove the submersible pump and cable accessories, then inject steam, operate huff and puff flowing production, whereafter lower the submersible pump to produce. Each 
steam stimulation operation needs complicated processes and to be of great time and labor cost. Plus, workover operation is needed when flowing production transits into artificial lifting, while the cold pressing in workover will do damage in formation and lead to sand production. Moreover, the killing fluid and workover operation cools down the well bore which greatly decreases the thermal recovery effects and shortens the validity period of steam stimulation. Thus, a new method of artificial lifting is urgently needed to meet the requirement of high-efficient development of offshore heavy oil.

To improve the recovery of offshore oilfield, we introduce the onshore rod pumping recovery technology-artificial lifting of conventional sucker rod pumping system into offshore oilfield recovery, forming the new technology of "heavy oil steam stimulation along with artificial lifting of conventional sucker rod pumping system."

\section{Study on key equipment of offshore heavy oil thermal recovery new technology}

If we can reduce the structure size of onshore heavy oil pumping unit to match the offshore platform, the mature onshore heavy oil development model can be the reference for offshore. Our project team successively carries out research and development on offshore miniature hydraulic pumping unit, and technological breakthrough for offshore wellhead and downhole equipment. Gradually, we form a new offshore heavy oil rod pumping technology—steam stimulation along with artificial lifting of conventional sucker rod pumping system. The mechanical heavy oil pump can integrate injection and production, thereby achieving the high-efficient offshore development as onshore oil recovery.

Artificial lifting of conventional sucker rod pumping system is the most widely used method in global oilfield production. Statistics show that $80 \%$ of onshore oil wells use this lifting method (Zhang 2010). To apply the mature onshore lifting in offshore platform, pumping unit out of the conventional pumping equipment is the key of new technology.

Pilot experimental offshore platform locates at the LD27-2 oilfield in the east of Bohai Sea. It has five layers of decks, among which, the bottom deck, medium deck and top deck are all $5 \mathrm{~m}$ high. Distance among well heads is $1.8 \mathrm{~m} \times 2.0 \mathrm{~m}$. Operation area of pumping unit on the platform is shown in Fig. 1.

Based on Fig. 1, operation space of pumping units on offshore platform can reach $10 \mathrm{~m}$ high, with a horizontal area of $1.8 \mathrm{~m} \times 2.0 \mathrm{~m}$. In accordance with wellhead limitation and workover operation, the new hydraulic pumping unit must be of compact structure and small site area. We

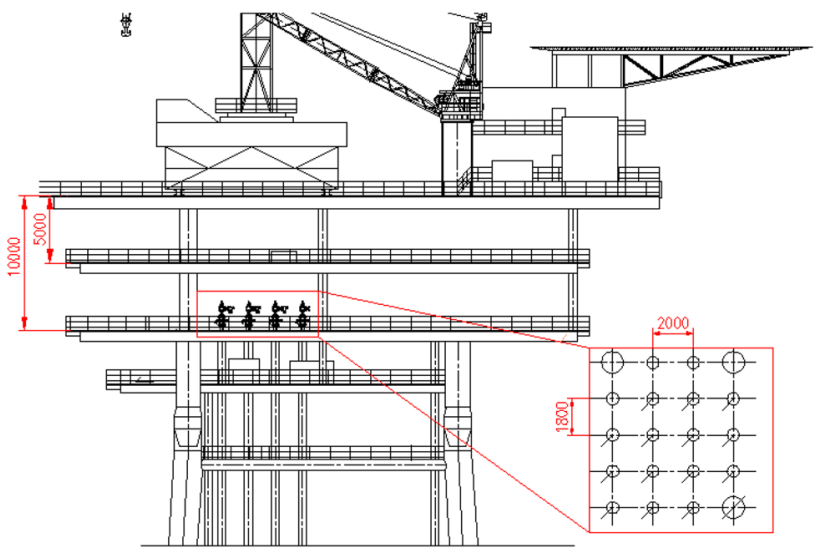

Fig. 1 Schematic diagram of aimed offshore platform working area

choose hydraulic cylinder to serve as power element. Unit height is reduced by the stroke lengthening of pulley system. The whole structure diagram is illustrated in Fig. 2, which mainly consist of base, combined cylinder, sheaves, accumulator cylinders, fluid control system, etc. The overall dimensions are $1.0 \mathrm{~m} \times 0.7 \mathrm{~m} \times 4.0 \mathrm{~m}$.

The pumping unit is installed on the mediate platform. In upstroke, piston rod of combined hydraulic cylinder extends outwards, and elevating belt is linked with polished rod by beam hanger, driving upward the sucker rod. In downstroke, sucker rod goes down and elevating belt presses back on piston rod, impressing the fluid in infusion cavity of combined cylinder back to accumulator cylinder then accumulating gravity potential energy. The energy will be released in upstroke to balance the loading.

During the upstroke operation, the electro-hydraulic proportional valve is in the lower position. The hydraulic oil flows through the hydraulic lock, gets pressed into the center bore of the combined cylinder, balances the load of the upstroke with the help of the hydraulic oil of the

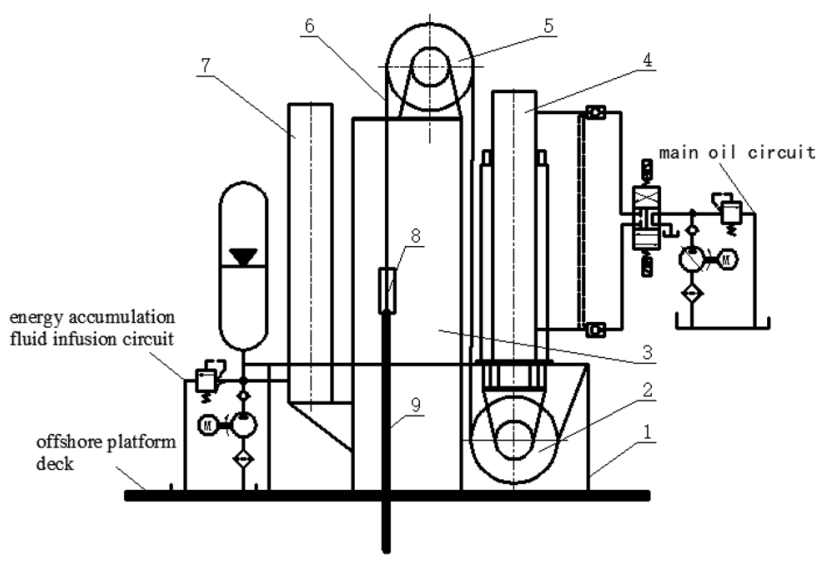

Fig. 2 Schematic diagram of offshore hydraulic pumping unit whole structure (1-base, 2-driving pulley, 3-frame, 4-combined cylinder, 5crown sheave, 6-elevating belt, 7 -accumulator cylinder, 8-beam hanger, 9-polished rod) 
balance hydraulic cylinder and the accumulator collectively, and pushes the load end to move upwards. Then the hydraulic oil of the side bore flows back into the oil tank through the hydraulic lock, indicating the end of the upstroke operation. While during the downstroke operation, the electro-hydraulic proportional valve is in the upper position, the hydraulic oil is pressed into the side bole of the combined cylinder through the hydraulic lock, pushing the load end to move upwards with the help of the load of the downstroke. The hydraulic oil in the mandrel of the combined cylinder is pressed into the energy storage device.

The performance of the pumping unit research is relatively mature, so the key research of the pumping unit is the structure miniaturization and low dwarf. For this purpose, we have carried out the research of hydraulic pumping unit. The first model is used to test the function in onshore well, the second to mimic the dwarf pumping unit in the laboratory, showed in Fig. 3.

\section{Offshore platform rod pumping wellhead safety technology}

Offshore platform, densely arranged and highly concentrated with production wells, equipment and personnel, is the living and working space of workers. Therefore, offshore well safety system has much higher requirements than onshore, and well safety is the prerequisite and guarantee of the implement of new technology (Espen et al. 2015). In "submersible pumping lifting" mode, the wellhead is normally closed, while under new technology it is
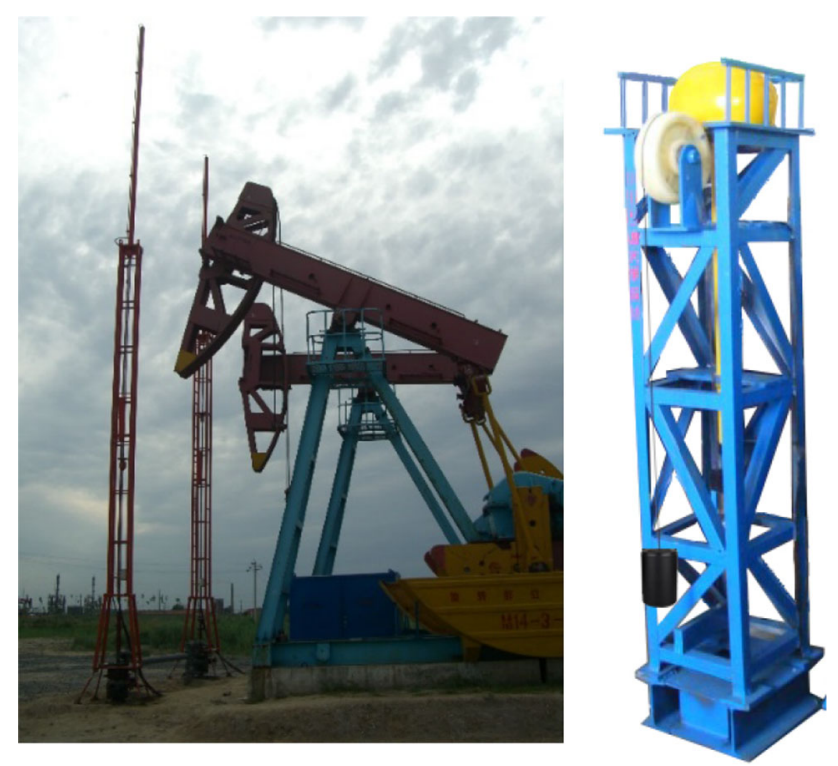

Fig. 3 Single cylinder upright pumping unit and laboratory model prototype dynamically sealed. Currently, there is no suitable equipment for offshore open-wellhead platform neither at home nor abroad.

The studied composite offshore rod pumping wellhead equipment has two main bodies, the upper packing centeradjustable wellhead structure and the lower rod broken automatic shut-in and manual sealing wellhead structure. The overall structure is shown in Fig. 4.

As shown in Fig. 4, in the composite wellhead equipment of offshore platform, the upper first part is mainly for dynamic sealing and deviation auto-adjusting of polished rod in normal operation. The sealing structure mainly includes packing press cap, packing press shell, packing box and packing. It holds tightly with the polished rod through press cap rotation and packing compression, to achieve wellhead dynamic sealing. Deviation auto-adjusting structure mainly involves ball-end, ball-end pedestal and ball-end press cover. The ball-end can swing arbitrarily by $0^{\circ}-15^{\circ}$ in the $360^{\circ}$ plane for deviation auto-adjustment.

The lower second part is again divided into two parts. The lower equipment mainly consists of gates (left gate and right gate), compression springs (left springs and right springs), sealing plug and so forth. Under normal working conditions, the gates hold the polished rod under the force of compression springs. The equipment has a function of floating center-adjusting for the springs on both sides, preventing partial wear of polished rod on wellhead. If it occurs extreme maritime conditions leading to capsizing of the platform and failure of polished rod, the gates will shut

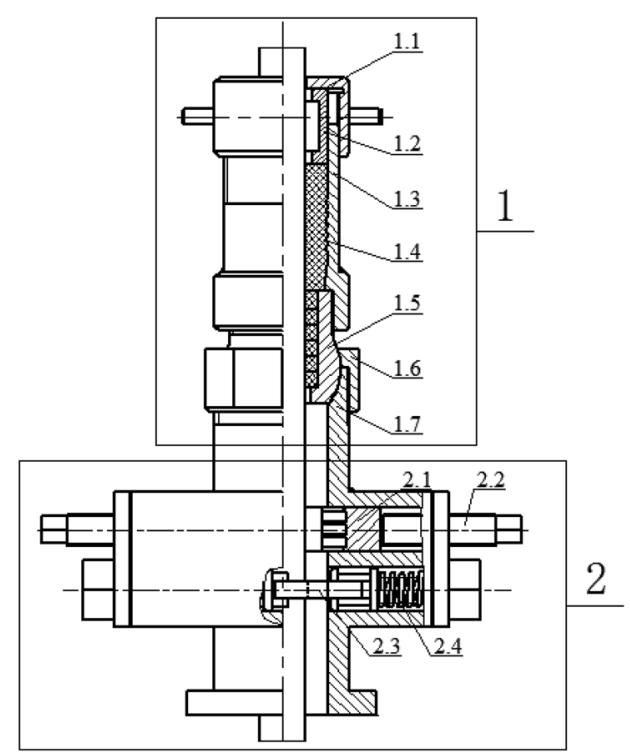

Fig. 4 Offshore composite wellhead equipment (1-packing centeradjustable wellhead structure: 1.1-packing press cap, 1.2-packing press shell, 1.3-packing box, 1.4-packing, 1.5-ball-end, 1.6-ball-end press cap, 1.7-ball-end pedestal; 2-rod broken automatic shut-in and manual sealing wellhead structure: 2.1-sealing ontology, 2.2-screw, 2.3-shut-in gate, 2.4-compression spring) 
in wellhead under the compression of springs. The upper part contains screw rod and sealing ontology. During pump-stopping and well sealing when upper packing wellhead structure stays static sealing situation, rotary screw pushes forward sealing ontology to hold polished rod tight and seal the wellhead.

Lower shut-in structure in offshore composite wellhead equipment is to safeguard the well safety manual shut-in structure out of which is vital for normal well shut-in, steam injection, platform evacuation, etc. Its structure reliability is the prerequisite of well shut-in. Inner fluid sealing structure and leakage theoretical research are the base. It is until the offshore produce-stopping that the shutin structure can work. Sealing ontology and polished rod are relative stationary, and they may only relatively slip under extreme working conditions, but with low slip amount and speed. Based on operational conditions above, offshore wellhead equipment uses straight-through labyrinth seal model.

Wellhead straight-through labyrinth seal model is shown as followed in Fig. 5.

In Fig. 5: $P_{\mathrm{i}}, P_{\mathrm{o}}$ are relatively inlet and outlet oil pressure. $H_{\mathrm{c}}, L_{\mathrm{c}}$ are distinctively sealing groove depth and width, with $\mathrm{mm}$ as the units. $H, L$ stands for spacing height and sealing tooth width, and the units of which are $\mathrm{mm}$.

Based on straight-through labyrinth seal structure, using fluid dynamics theory, we establish a leakage model of the sealing structure.

$\Delta P=n \rho \frac{Q^{2}}{2 A_{1}^{2}}\left[\left(1+\frac{1}{n}\right) \lambda_{1} \frac{L}{2 H}+\lambda_{2} \frac{L_{\mathrm{C}}}{2\left(H+H_{\mathrm{c}}\right)}\left(\frac{A_{1}}{A_{2}}\right)^{2}+2\left(1-\frac{A_{1}}{A_{2}}\right)^{2}\right]$

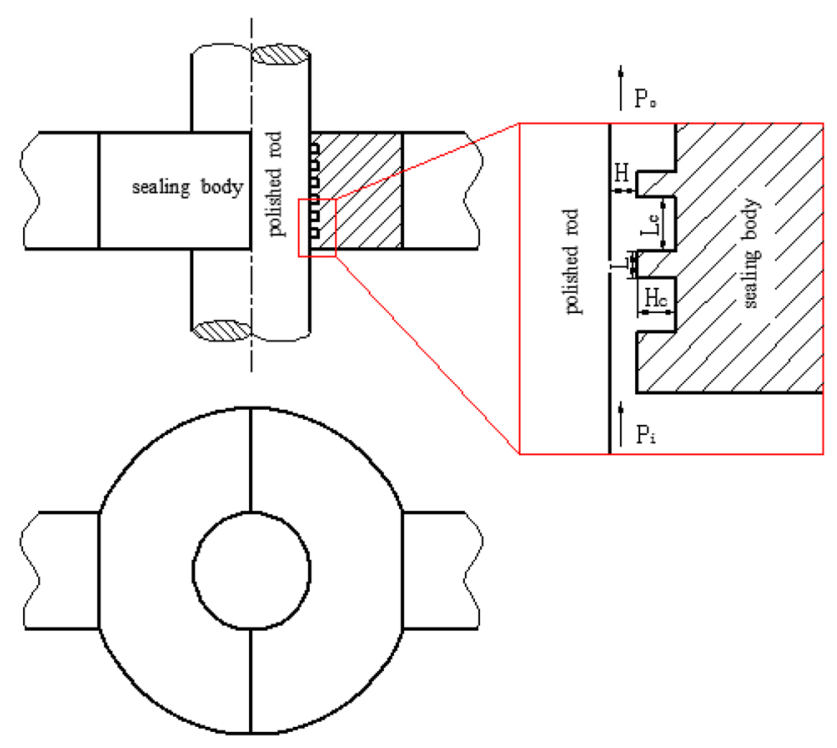

Fig. 5 Diagram of straight-through wellhead labyrinth seal model
In which: $\Delta P$-leaked fluid pressure loss $(\mathrm{Pa}) ; Q$ labyrinth sealed fluid leakage $\left(\mathrm{m}^{3} / \mathrm{s}\right) ; n$-straight labyrinth seal series, $\rho$-leaked fluid density $\left(\mathrm{kg} / \mathrm{m}^{3}\right), A_{1}$-seal tooth annulus spacing cross-sectional area $\left(\mathrm{m}^{2}\right) ; A_{2}$-groove annulus spacing cross-sectional area $\left(\mathrm{m}^{2}\right), \lambda_{1}$-frictional resistant coefficient of sealed teeth spacing, $\lambda_{2}$-frictional resistant coefficient of sealed groove.

For the matching wellhead of polished rod (diameter: $28 \mathrm{~mm}$ ) based on mathematical model (1), we can determine the structure parameters of the straight-through labyrinth sealing as follows: sealing space length $L=4 \mathrm{~mm}$, sealing groove depth $H_{\mathrm{c}}=2 \mathrm{~mm}$, groove width $L_{\mathrm{c}}=6 \mathrm{~mm}$, sealing series $n=4$. Leakage under $0.1 \mathrm{~mm}$ spacing and high pressure of $10 \mathrm{MPa}$ is only $2.728 \times 10^{-5} \mathrm{~m}^{3} / \mathrm{s}$, meaning this equipment can achieve wellhead shut-in.

\section{Offshore platform rod pumping downhole safety technology}

Under extreme disaster, offshore platform may suffer collapse and wellhead damage, so downhole sealing equipment must be designed (Dev et al. 2016a, b). The new offshore platform heavy oil recovery technology replaces electronic submersible pump with rod pump, forming an annular space between tubing and sucker rod, causing technological difficulty for reliable downhole sealing and platform evacuation.

For the need of wellbore sealing in rod pumping, the study designs downhole safety equipment, consisting of tubing ontology, guide cone, high-temperature sealed rubber sleeve, micro-hydraulic cylinders, die spring, standard collar short-connection and so forth. The high-temperature sealed rubber sleeve and micro-hydraulic cylinders along with accessories assemble the sealing main body, installed on well bore safety equipment tubing ontology through bolted connection. The guide cone is mounted in place, and each end's coupling is welding sealed and packaged.

The overall structure is shown in Fig. 6.

Overall inner diameter of downhole well safety equipment is identical with tubing inner diameter. Coupling short-connection uses standard couplings, and the equipment goes down into well as tubing to depth of $100 \mathrm{~m}$. Working deck injects fluid to rod cavity of micro-hydraulic cylinder, then piston compresses die spring, and hightemperature sealed rubber sleeve lowers with piston rod, opening the annular space between sucker rod and tubing. It maintains the working deck control pressure, also known as to maintain opening condition.

When rod cavity of hydraulic cylinder releases pressure, piston rod extends outward by the function of die spring, and high-temperature sealed rubber sleeve enters the annular space along the guide cone, deforming under piston 


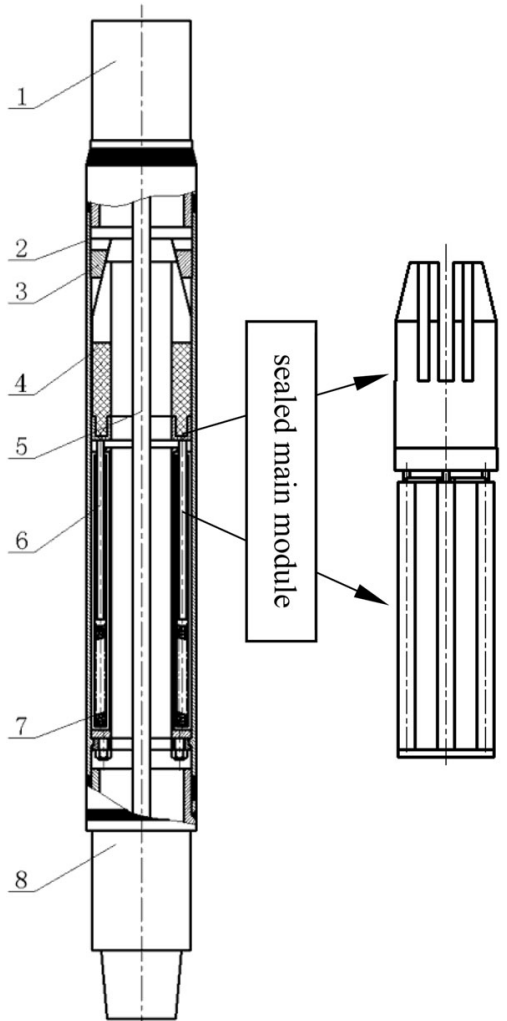

Fig. 6 Structure diagram of downhole safety equipment (1-inner cone coupling short-connection, 2-tubing ontology, 3-guide cone, 4high-temperature sealed rubber sleeve, 5-sucker rod, 6-micro hydraulic cylinders, 7-die spring, 8-outer cone coupling shortconnection)

thrust and guide cone extrusion, then enclasps the sucker rod and shuts the well in. Under extreme conditions, rod cavity releases pressure and fluid runs into rodless cavity, achieving high pressure shut-in under combined action of spring elasticity and hydraulic push.

The shut-in effect of the wellbore safety equipment is closely related to the structure and performance of the high-temperature sealed rubber sleeve. The bad well condition of thermal recovered heavy oil wells have higher requirements for the high-temperature resistance, highpressure resistance and wear resistance of the sealing components. The high-temperature sealing cylinder in Fig. 6 is made of a new type of high-temperature and highpressure rubber material, which is a modified material based on the existing fluorine rubber. Using bisphenol sulfuration system, adding vulcanizate, bisphenol AF, BPP, spray carbon black, light $\mathrm{MgO}, \mathrm{Ca}(\mathrm{OH})_{2}$ and appropriate amount of molybdenum disulfide and graphite fiber to improve the wear resistance of rubber sleeve (Sun et al. 2012), the modified fluorine rubber has a temperature resistance of above $300{ }^{\circ} \mathrm{C}$.

The structural dimensions of the rubber sleeve are shown in Fig. 7.
Based on Fig. 7, the sectional area equation of rubber sleeve is:

$$
f_{1}(z)= \begin{cases}\frac{1}{4} \pi\left[\left(96+2 \cot 75^{\circ} \cdot z\right)^{2}-86^{2}\right]-5 \times A_{q}, & 0 \leq z \leq 20 \cdot \tan 75^{\circ} \\ \frac{1}{4} \pi\left(136^{2}-86^{2}\right)-2.515 \times 10^{3}, & 20 \cdot \tan 75^{\circ}<z<160 \\ \frac{1}{4} \pi\left(136^{2}-86^{2}\right), & 160 \leq z \leq 280\end{cases}
$$

In which:

$$
\begin{aligned}
A_{q}= & \left(\theta_{1} \times\left(48+z \cdot \cot 75^{\circ}\right)^{2}\right)-\frac{100}{\tan \theta_{1}}+20 \\
& \times\left(48+z \cdot \cot 75^{\circ}\right) \cdot \cos \theta_{1}-852.184
\end{aligned}
$$

$\theta_{1}=\arcsin \frac{10}{48+z \cdot \cot 75^{\circ}}$

$f_{1}(z)$-cross-sectional area of rubber tube $\left(\mathrm{mm}^{2}\right), z$-longitudinal coordinate $(\mathrm{mm}), A_{q}$-sectional code of hollow section $\left(\mathrm{mm}^{2}\right)$.

Structure of the guide cone, which is matched with the high-temperature sealed rubber sleeve, is shown in Fig. 8.

Based on Fig. 8, the section area equation of the guide cone inner annulus is:
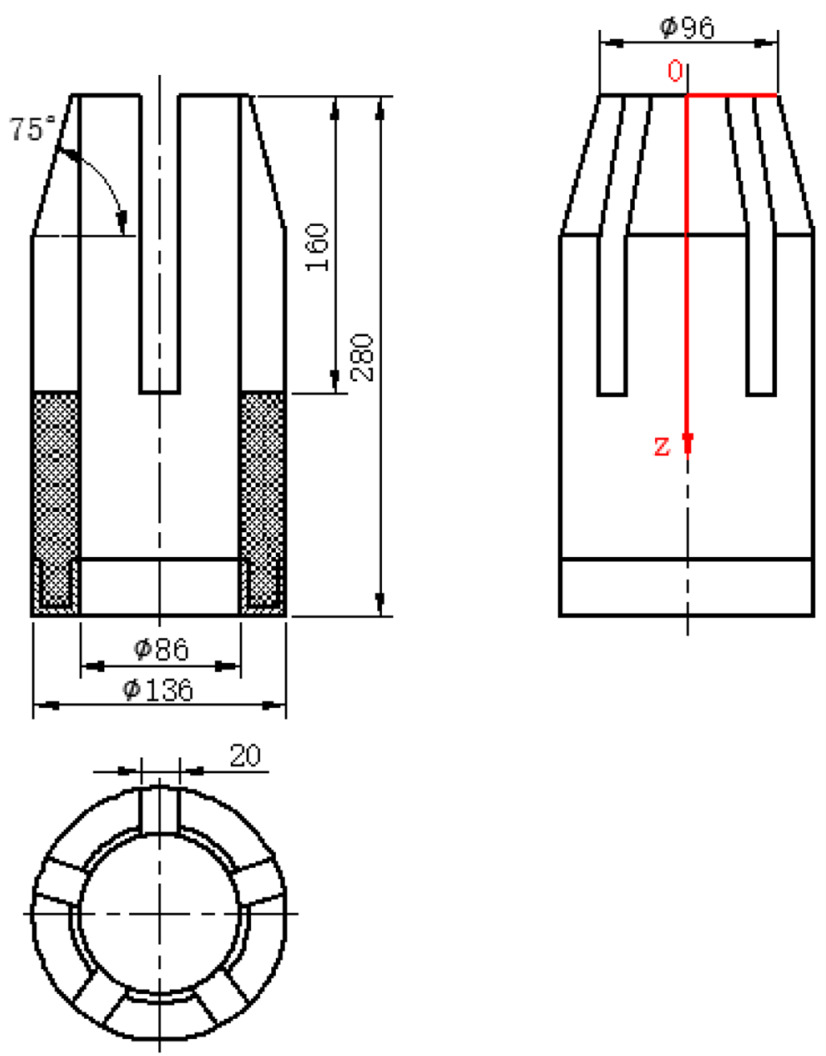

Fig. 7 Structure diagram of high-temperature sealed rubber sleeve 


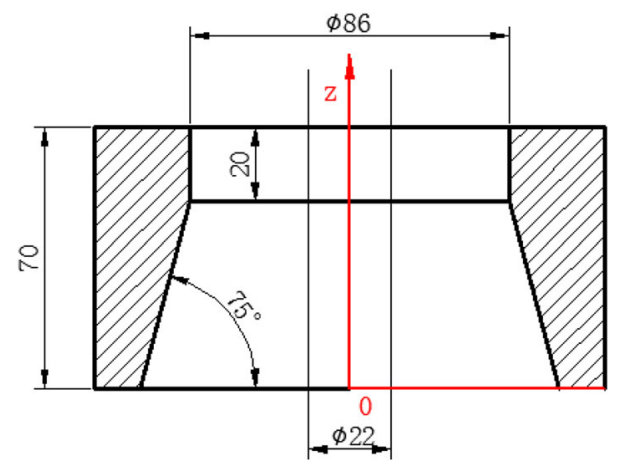

Fig. 8 Structure diagram of guide cone

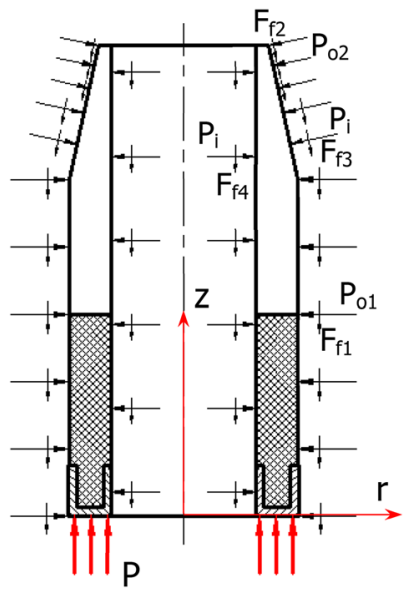

Fig. 9 Force diagram of rubber sleeve during setting

$f_{2}(z)= \begin{cases}\frac{1}{4} \pi\left[(86+0.54 \cdot(50-z))^{2}-22^{2}\right], & 0 \leq z \leq 50 \\ \frac{1}{4} \pi\left(86^{2}-22^{2}\right), & 50<z \leq 70\end{cases}$

In which: $f_{2}(z)$-section area of the guide cone inner annulus $\left(\mathrm{mm}^{2}\right)$.

Rubber cylinder, as incompressible nonlinear material with large deformation, the deformation of which can be calculated with the volume invariance principle. By Eq. (2) and Eq. (3), when $z=65.597 \mathrm{~mm}$, the sectional area of rubber cylinder is equal to sectional area of the inner annulus of guide cone connection.

\section{Force analysis of wellbore setting}

The rubber sleeve is of axisymmetric structure. The force acting of wellbore setting is shown in Fig. 9.

In Fig. 9: $P$-the axial pressure on rubber sleeve (MPa); $P_{o 1}$-pressure on rubber sleeve from the ontology (MPa);
$P_{o 2}$-the pressure from the inner conical surface on the sleeve $(\mathrm{MPa}) ; P_{i}$ stands for oil well pressure $(\mathrm{MPa}) ; F_{f 1}, F_{f 2}$ are, respectively, the corresponding friction force of $P_{o 1}$, $P_{o 2}(\mathrm{~N}) ; F_{f 3}, F_{f 4}$ are, respectively, outer and inner friction of the sleeve $(\mathrm{N})$.

Friction between rubber sleeve and ontology $F_{f 1}$ :

$F_{f 1}=\int_{0}^{280-20 \cdot \tan 75^{\circ}} P_{o 1} \cdot \mu_{1} \cdot 2 \pi \cdot 68 \cdot \mathrm{d} z$

In which: $\mu_{1}$-friction coefficient between rubber sleeve and the ontology.

Friction between rubber sleeve outer conical surface and guide cone inner conical surface $F_{f 2}$ :

$F_{f 2}=\int_{230+5 \cdot \tan 75^{\circ}}^{280} P_{o 2} \cdot \mu_{1} \cdot 2 \pi \cdot\left[48+(280-z) \cot 75^{\circ}\right] \cdot \mathrm{d} z$

Friction on outer rubber sleeve conical surface from oil surface $F_{f 3}$ :

$F_{f 3}=\int_{280-20 \cdot \tan 75^{\circ}}^{230+5 \cdot \tan 75} P_{i} \cdot \mu_{2} \cdot 2 \pi \cdot[50+(280-z) \cot 78] \cdot \mathrm{d} z$

In which: $\mu_{2}$-friction coefficient between rubber sleeve and oil surface.

Friction on rubber sleeve inner conical surface from oil surface $F_{f 4}$ :

$F_{f 4}=\int_{0}^{280} P_{i} \cdot \mu_{2} \cdot 2 \pi \cdot a \cdot \mathrm{d} z$

By the promotion of axial force $p$, rubber sleeve goes up and deforms, sealing the annulus between the tubing and sucker rod. Force diagram of rubber sleeve after setting is shown in Fig. 10.

In Fig. 10: $p_{\mathrm{u}}$-the oil pressure for the upper part of the rubber sleeve $(\mathrm{MPa})$; $p_{1}$-pressure on rubber sleeve of tubing ontology $(\mathrm{MPa}) ; p_{2}$-pressure of conical surface of guide cone on rubber sleeve (MPa); $p_{3}$-the pressure of cylindrical surface of guide cone on rubber sleeve (MPa); $p_{4}$ is pressure of sucker rod on rubber sleeve (MPa); $F_{1}, F_{2}, F_{3}, F_{4}$ are, respectively, frictions by $p_{1}, p_{2}, p_{3}, p_{4}(\mathrm{~N})$.

The rubber sleeve is an incompressible elastomer. Under setting and according to the radial force balance, we have:

$P_{1}=P_{i}, P_{2}=P_{i}, P_{3}=P_{4}$

When the axial balance of the rubber sleeve is obtained, we have: 


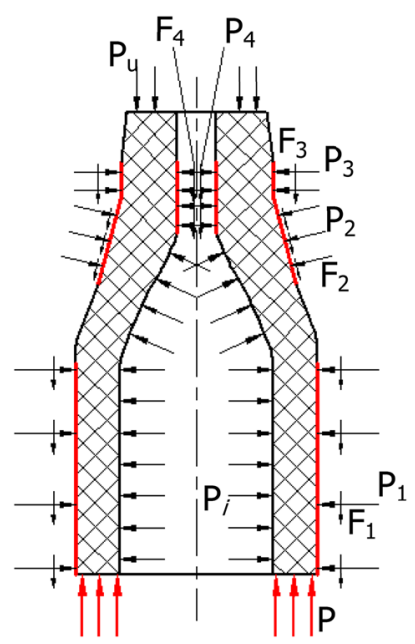

Fig. 10 Force diagram after rubber sleeve setting

$$
\begin{aligned}
P S+P_{i} S_{d}= & F_{1}+F_{2} \cdot \cos 75^{\circ}+F_{3}+F_{4}+P_{u} S_{u} \\
= & \left(P_{1} S_{1}+P_{2} S_{2} \cdot \cos 75^{\circ}+P_{3} S_{3}+P_{4} S_{4}\right) \mu_{1} \\
& +P_{u} S_{u}
\end{aligned}
$$

In which: $S$-end area of rubber sleeve $\left(\mathrm{mm}^{2}\right), S_{\mathrm{d}}$-equivalent area of lower part oil pressure of rubber sleeve $\left(\mathrm{mm}^{2}\right), S_{\mathrm{u}^{-}}$ equivalent area of upper part oil pressure of rubber sleeve $\left(\mathrm{mm}^{2}\right), A_{1}, A_{2}, A_{3}, A_{4}$ are, respectively, area of force of $p_{1}$, $p_{2}, p_{3}, p_{4}\left(\mathrm{~mm}^{2}\right), \mu_{1}$-the dynamical friction factor, with $\mu_{1}=0.1$.

Wellbore safety equipment is installed at $100 \mathrm{~m}$ under the wellhead. Upper oil pressure of rubber sleeve, $P_{u}=P_{0}+\rho g h=P_{0}+9.408 \times 10^{5} \mathrm{~Pa} ; \quad\left(P_{0}\right.$-wellhead oil pressure, is normally 1.0-1.5 MPa; $\rho$-heavy oil density of Bohai Bay area (Shi et al. 2014), is $0.94-0.98 \mathrm{~g} / \mathrm{cm}^{3}$ ).

At the moment of shut-in, $P_{i}=P_{u}$.

By Eq. (9), when the normal oil pressure is $2 \mathrm{MPa}$, the shut-in pressure is $1.027 \mathrm{kN}$. After shut-in and wellhead venting, upper pressure of rubber sleeve $p_{\mathrm{u}}$ stays, while the lower part pressure varies with well conditions. Requirement for setting is $P_{3}=P_{4} \geq P_{i}$, which can also be described as:

$P S \geq P_{i}\left(S_{1}+S_{2} \cdot \cos 75^{\circ}+S_{3}+S_{4}\right) f_{1}+P_{\mathrm{u}} S_{\mathrm{u}}-P_{i} S_{d}$

After shut-in, when well pressure $P_{i} \leq 1.025 \mathrm{MPa}$, the hydraulic cylinder must keep the pressure. The higher the well pressure $P_{i}$ is, the lower the piston rod thrust is required; when the well pressure is above $1.025 \mathrm{MPa}$, the wellbore safety equipment can achieve auto-sealing by well pressure. And the higher the pressure is, the better the auto-sealing is.
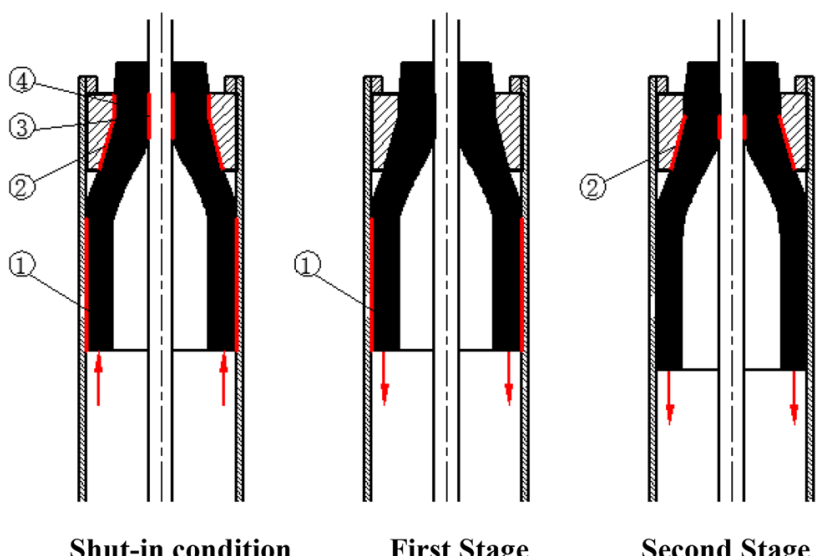

Shut-in condition

First Stage

Second Stage
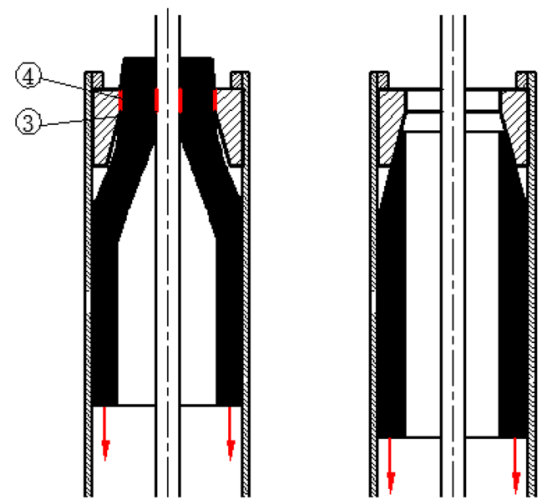

Third stage

Well-opening condition

Fig. 11 Unsealing process of rubber sleeve

\section{Analysis of wellbore unsealing}

As shown in Fig. 11, when the rubber sleeve unseals, deformation goes through 3 stages.

First, it overcomes the static friction force between part (1) of rubber sleeve and the tubing. With the axial deformation of the rubber sleeve, the static friction changes into sliding friction until the separation. Part (2) of the rubber sleeve is of cone structure. After the deformation of the first stage, part (2) of the sleeve will automatically separate from the conical surface of the guide cone. Under the pull of piston rod, the rubber sleeve goes down after overcoming the squeezing and friction of part (3) and (4), opening the annulus between tubing and sucker rod.

Maximum frictional resistance of stage 1:

$F_{1 \max }=P_{1} S_{1} f_{1}$

Maximum frictional resistance of stage 3:

$F_{3 \max }=\left(P_{3} S_{3}+P_{4} S_{4}\right) f_{1}+\left(P_{i}-P_{u}\right) S_{u}$

The relation between the well opening force and the oil well pressure of the wellbore safety equipment at each stage is shown in Fig. 12. 


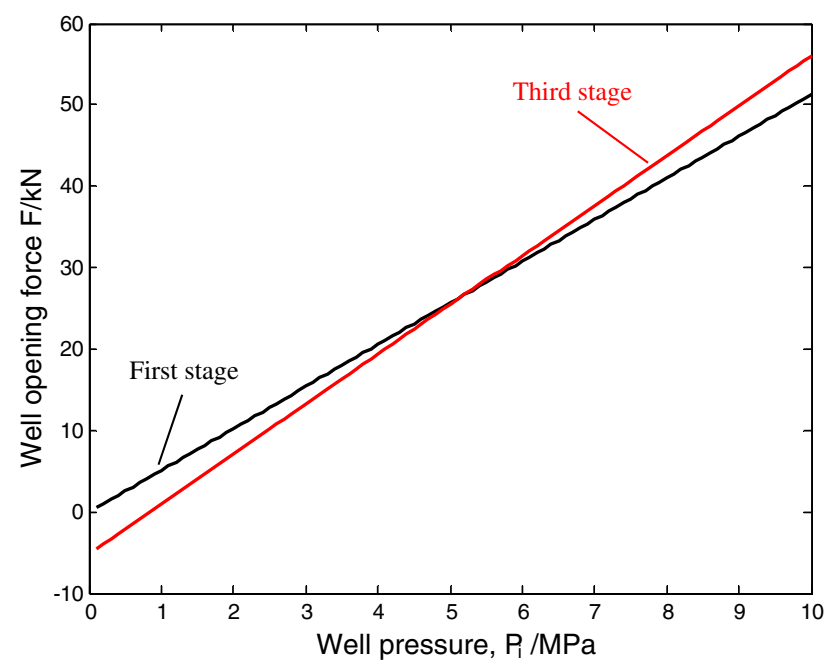

Fig. 12 Relationship between well opening force and oil well pressure

As shown in Fig. 12, when the well pressure is lower than 5.208 MPa, the maximum opening force of the wellbore safety device is determined by the frictional force at the first stage. When the well pressure is greater than $5.208 \mathrm{MPa}$, the maximum opening force is determined by the frictional force at the third stage. When the normal oil well pressure is $2 \mathrm{MPa}$, the opening force is $10.254 \mathrm{kN}$. And the opening force of the high-pressure oil well at $10 \mathrm{MPa}$ is $55.969 \mathrm{kN}$.

\section{Conclusion}

1. High-efficient heavy oil recovery is a technological difficulty for offshore oilfields at home and abroad. Referencing the mature onshore heavy oil production technology, for the first time, the study comes up with the new rod pumping technology and heavy oil steam stimulation along with artificial lifting of conventional rod sucker pumping system.

2. According to offshore platform space, we have designed one new kind of miniature hydraulic pumping unit with long-stroke, low pumping speed and compact structure. It coordinates combined cylinders and accumulators to achieve loading balance in upstroke and downstroke.

3. We developed composite wellhead equipment for offshore platform, which can operate normal dynamic sealing, rod broken automatic shut-in, produce-stopping manual well sealing and other functions. Based on fluid mechanics, we established a wellhead sealing leakage model and obtain the structure parameters of wellhead when coordinated with $28 \mathrm{~mm}$ polished rod.
4. We designed the downhole safety equipment for sealing annular space between pipe and sucker rod and form the corresponding patent. It achieves setting shut-in and well opening through high-temperature sealed rubber sleeve extrusion deformation. Based on volume-unchanging property of incompressible materials large nonlinear deformation and Lame formula, we established the mechanical model for the rubber sleeve.

Through the researches above, we have designed a series of the offshore rod pumping equipment and form the key technology of offshore well safety, providing not only equipment but theoretical support for offshore heavy oil thermal recovery.

Funding National science and technology major projects of oil and gas (2016ZX05066, 2016ZX05042), Natural science fund project of Shandong province (ZR2014E1015).

\section{Compliance with ethical standards}

Conflict of interest The authors confirm that this article content has no conflict of interest.

Open Access This article is distributed under the terms of the Creative Commons Attribution 4.0 International License (http:// creativecommons.org/licenses/by/4.0/), which permits unrestricted use, distribution, and reproduction in any medium, provided you give appropriate credit to the original author(s) and the source, provide a link to the Creative Commons license, and indicate if changes were made.

\section{References}

Denney D (2012) Heavy oil well testing with an ESP, Offshore UK. J Pet Technol 64(3):94-99

Dev B, Samudrala O, Wang JF (2016a) Characterization of leak rates in thermoplastic barrier valve seals under high static and cyclic pressure load. J Pet Sci Eng 145:279-289

Dev B, Samudrala O, Wang JF (2016b) Comparison of leakage characteristics of viton and polytetrafluoroethylene seals in gaslift valve applications. J Energy Resour Technol 139(1):012906

Dong ZG, Zhang MJ, Zhang X, Pang XD (2008) Study on reasonable choice of electric submersible pump. Acta Pet Sin 29(1):128-131

Espen O, Sturle N, Sindre H (2015) Exploring relationships between organizational factors and hydrocarbon leaks on offshore platform. Saf Sci 80:301-309

Gholamzadeh MA, Hashemi P, Dorostkar MJ (2010) New improved oil recovery from heavy and semi-heavy oil reservoir by implementing immiscible heated WAG injection. In: SPE 132785

Guo YH, Zhou XH, Li JP, Ling YX, Yang JM (2010) Crude features and origins of the Neogene heavy oil reservoirs in the Bohai Bay. Oil Gas Geol 31(3):375-380

Lea JF, Llc PT, Winkler HW (2011) What's new in artificial lift. World Oil 23(5):231-243

Li P, Liu ZL, Zou J, Liu HY, Yu JF, Fang YT (2016) Injection and production project of pilot test on steam huff-puff in oilfield LD27-2 Bohai Sea. Acta Pet Sin 37(2):242-247 
Shariatinia Z, Haghighi M, Feiznia S, Alizai AH, Levresse G (2013) Hydrocarbon migration in the Zagros Basin, offshore Iran, for understanding the fluid flow in the Oligocene-Miocene carbonate reservoirs. Russ Geol Geophys 54(1):64-81

Shi YZ, Xie T, Fu Y (2014) A new method to determine the formation oil viscosity for Bohai heavy oilfield. Complex Hydrocarbon Reserv 7(2):54-56

Sun SD, Chen G, Li P, Wei QC, Zhang XJ, Ma D (2012) Development and application of a new type of rubber tube with high temperature and high pressure. Oil Drill Prod Technol 34(S0):81-83

Sun Y, Zhong L, Hou J, Sun Y, Liu H (2013) Case study: thermal enhance Bohai offshore heavy oil recovery by costimulation of steam and gases. In: SPE Heavy Oil Conference-Canada, Calgary, Alberta, Canada

Terdre N (2011) Peregrino producing heavy oil for Statoil offshore Brazil. Offshore 71(12):36

Zhang WH (2010) Optimal design of sucker rod pumping system parameters in horizontal well. Xi' an Shiyou University

Zhou SW (2007) The study and application of new mode of effective development of offshore heavy oil field. J Southwest Pet Univ 29(5):1-4

Publisher's Note Springer Nature remains neutral with regard to jurisdictional claims in published maps and institutional affiliations. 